\title{
Three-Point Bending Response of Corrugated Core Metallic Sandwich Panels Having Different Core Configurations - An Experimental Study
}

\author{
Erman Zurnaci \\ Dr. Engin Pak Cumayeri Vocational School, \\ Duzce University, Duzce, Turkey \\ ermanzurnaci@duzce.edu.tr \\ Muammer Nalbant \\ Faculty of Technology, \\ Gazi University, Ankara, Turkey \\ nalbant@gazi.edu.tr
}

\author{
Hasan Gokkaya \\ Mechanical Engineering Department, \\ Karabuk University, Karabuk, Turkey \\ hgokkaya@karabuk.edu.tr \\ Gokhan Sur \\ Mechanical Engineering Department, \\ Karabuk University, Karabuk, Turkey \\ gokhansur@karabuk.edu.tr
}

\begin{abstract}
Bending response of corrugated core metallic sandwich panels was studied experimentally under three-point bending loading. Two different core configurations were used: the corrugated monolithic core and the corrugated sliced core. The trapezoidal corrugated cores were manufactured from aluminum sheets via a sheet metal bending mould. After the sandwich panel samples were prepared, they were subjected to three-point bending tests. The load and displacement responses of the sandwich panels having different core configurations were obtained from the experimental testing. The influence of the core configuration on the three-point bending response and failure modes was then investigated. The experimental results revealed that the corrugated sliced core configuration exhibited an improved bending performance compared to the corrugated monolithic core configuration.
\end{abstract}

Keywords-bending response; failure modes; three-point bending; metallic sandwich panel; corrugated core configurations

\section{INTRODUCTION}

Sandwich panels consist of thin, stiff surface plates and a lightweight core. The core and surface plates of the sandwich panels are made from different materials including metal, polymer, fiber reinforced polymer, and balsa [1]. Sandwich panel cores are produced in different forms such as corrugated, lattice truss, honeycomb and foam cores. The surface plates show resistance to in-plane and lateral loads, whereas the sandwich panel core increases strength and contributes to important structural properties such as durability [2]. Metallic sandwich panels having corrugated cores exhibit a high bending strength and stiffness-to-weight ratio and for this reason they are used as structural components in a number of industries including defence, transportation, and space [3-6]. The bending strength of sandwich panels is related to the core form [7]. The corrugated core form is composed of continuously repeating unit cells. The corrugated core form has a low specific weight and increases the resistance and moment of inertia without greatly increasing the weight of the sandwich panel [8] in addition to preventing shear and bending.

In recent years, the bending performance and failure mechanism of corrugated sandwich panels has been researched extensively. For example, authors in [9] conducted an analysis of the bending behavior of a corrugated core sandwich panel with various boundary conditions using the Mindlin-Reissner plate theory. Moreover, they investigated the effects of several geometric parameters on the rigidity and state of the sandwich panel, observing some new phenomena in their experimental studies. Authors in [10] proposed a bi-directionally corrugated core design to reduce anisotropic behaviors of sandwich panels under bending load. They carried out three-point bending tests for different core orientations. Test results revealed that sandwich panels having bi-directionally corrugated cores showed quasi-isotopic bending behaviors and structural performances. Authors in [8] analytically and experimentally studied the tensile and bending characteristics of composite corrugated core sandwich panels and compared the experimental test results with the analytical ones. Loaddisplacement curves were obtained as a result of the three point bending test applied to the sandwich panels. The resulting curves revealed two different types of deformation: pure bending and combined bending. In addition, the results showed that core thickness affects the mechanical behavior of the core in the tension state. Authors in [11] studied the behavior of mild steel structural beams having a corrugated web under a three-point bending test. They investigated the semi-circular web corrugation in different directions of the beam experimentally and numerically. The results showed that the vertical-corrugated web-beam could be moved between higher moments. They also found that increasing the radius of the corrugation curvature of the groove caused higher bending stiffness. Authors in [12] investigated the quasi-static threepoint bending response and deformation modes of metallic

Corresponding author: Erman Zurnaci 
sandwich panels having a Y-frame and a corrugated core. They investigated the indentation strength of the sandwich beams having a Y-frame core. The experimental and numerical studies revealed that the initial collapse strength of the beams was directed by the indentation of the cores' geometry. The present study aims to explore the effect of different core configurations on the bending response of metallic sandwich panels under three-point bending loading. Metallic sandwich panel samples having corrugated monolithic core and corrugated sliced core configurations were produced. Three-point bending tests were conducted experimentally. Finally, the bending responses and failure modes of the sandwich panels having different core configurations were examined.

\section{EXPERIMENTAL WORK}

\section{A. Experimental Samples}

In this study, two types of sandwich panel samples, one type with corrugated monolithic core (CMC) and another with corrugated sliced core (CSC) configurations were used. An isometric view of the core configurations is given in Figure 1. The corrugated sliced core was produced by slicing the corrugated monolithic core and placing it on the surface plate of the panel in different directions and angles. Trapezoidal geometry was determined as the core form. The geometrical parameters of a core unit cell are given in Figure 2.

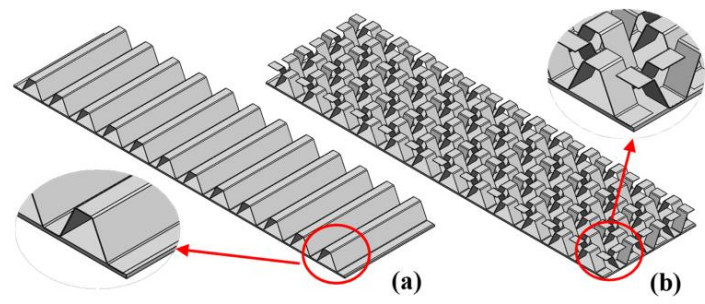

Fig. 1. Isometric view of the core configurations: (a) CMC and (b) CSC

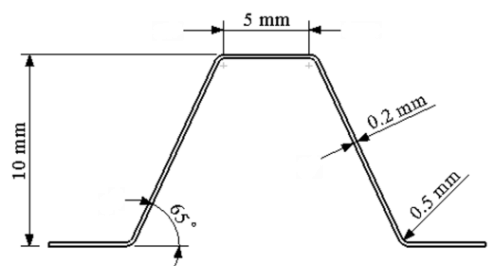

Fig. 2. Geometrical parameters of the core unit cell

Aluminum $1050 \mathrm{H} 14$ sheets were used as the core and surface plate material of the sandwich panel samples. The thickness of the core and surface plates were respectively $0.2 \mathrm{~mm}$ and $1 \mathrm{~mm}$. The material properties of the Aluminum $1050 \mathrm{H} 14$ sheet are listed in Table I.

TABLE I. ALUMINUM 1050 H14 PROPERTIES

\begin{tabular}{|c|c|c|c|c|}
\hline $\begin{array}{c}\text { Density } \\
\left(\mathbf{k g} / \mathbf{m}^{\mathbf{3}}\right)\end{array}$ & $\begin{array}{c}\text { Elastic modulus } \\
(\mathbf{G P a})\end{array}$ & $\begin{array}{c}\text { Poisson } \\
\text { ratio }\end{array}$ & $\begin{array}{c}\text { Yield stress } \\
\text { (MPa) }\end{array}$ & $\begin{array}{c}\text { Ultimate } \\
\text { stress (MPa) }\end{array}$ \\
\hline 2634 & 40 & 0.33 & 108 & 100 \\
\hline
\end{tabular}

The aluminum sheets were cut in widths of $64 \mathrm{~mm}$ and $6.8 \mathrm{~mm}$ to form the configurations of the CMC and CSC, respectively (Figure 3(a)). The sandwich panel corrugated cores were then manufactured from cut aluminum sheets using a custom-made bending mould (Figure 3(b)).

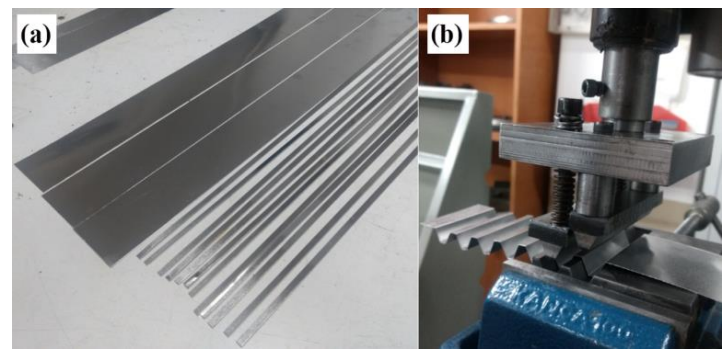

Fig. 3. Corrugated core production: (a) cutting the aluminum sheets and (b) moulding the corrugated cores

Each sandwich panel sample was made of three and twelve unit cells in the transverse and in the longitudinal direction respectively. The core and surface plates were assembled using Araldite 2015 two-component epoxy adhesive. The prepared samples were kept for more than $24 \mathrm{~h}$ under a specified press force at room temperature in order to ensure that the adhesive was completely cured. For evaluating the bending response of the sandwich panel, a total of six samples were prepared, three for each core configuration. The samples size was $244 \mathrm{~mm}$ in length, $64 \mathrm{~mm}$ in width and $12 \mathrm{~mm}$ thick. Average weights $(w)$ of the samples were $97.640 \mathrm{~g}$ and $100.760 \mathrm{~g}$ respectively for the sequentially corrugated monolithic core and corrugated sliced core sandwich panel samples. The prepared samples having different core configurations are displayed in Figure 4.

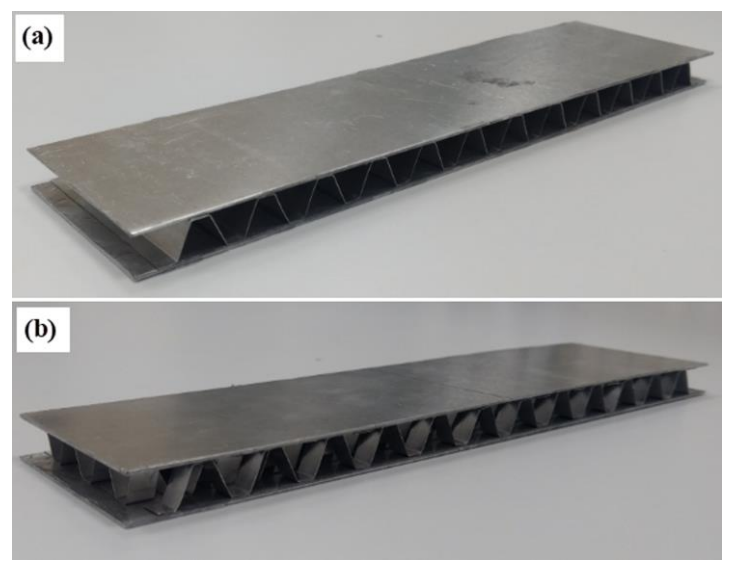

Fig. 4. Experimental samples of metallic sandwich panels: (a) CMC and (b) CSC

\section{B. Three-Point Bending Test}

The three-point bending tests were conducted on Shimadzu Autograph AGS-X testing machine with a capacity of $100 \mathrm{kN}$ at loading rate of $2 \mathrm{~mm} / \mathrm{min}$ (Figure 5). The tests were carried out in accordance with ASTM C393/C393M-16 standard [13]. An impact roller with a diameter of $10 \mathrm{~mm}$ and a support roller with a diameter of $30 \mathrm{~mm}$ with span length of $150 \mathrm{~mm}$ were used for the bending tests. The experimental setup for the 
three-point bending testing of the sandwich panel samples is shown in Figure 6. The tests were ended when the deformation value reached $12 \mathrm{~mm}$. At least three tests were conducted for each core configuration, and the averages of the measurements were calculated to ensure the accuracy and reproducibility of the test results. Load-displacement curves were recorded from the experimental tests.

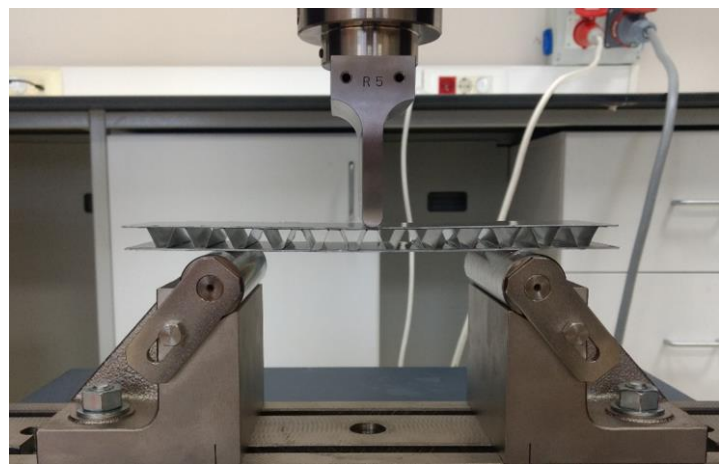

Fig. 5. Three-point bending test machine

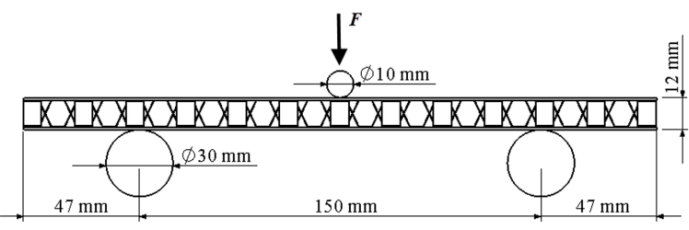

Fig. 6. Experimental setup of the three-point bending test

\section{RESULTS AND DISCUSSION}

\section{A. Bending Responses}

The load-displacement curves represent the bending responses of the sandwich panels under the influence of bending load. The load-displacement curves are given in Figure 7. Bending strength and specific bending strength values were calculated for the evaluation of the bending responses of the sandwich panels having different core configurations. The bending strength value $\sigma$ was calculated using (1):

$$
\sigma=\frac{3 F l}{2 b h^{2}}
$$

where $F$ is the peak load obtained from the load-displacement curve, $l$ is the span length, $b$ is the width of the sample and $h$ the thickness of the sample.

The specific bending strength value $\sigma_{S}$ is the ratio of the bending strength to the weight $(w)$ of the sandwich panel samples:

$$
\sigma_{S}=\sigma / w
$$

Examination of the curves shows that the sandwich panel having CSC configuration exhibited higher bending strength. In addition, fluctuations occurred in the load-displacement curve of the sandwich panel having CMC configuration. The bending response values of the samples are given in Table II. The sandwich panels having CMC configuration began to bend after a peak load of $169.11 \mathrm{kN}$, whereas the CSC configuration increased the bending strength of the sandwich panels by $117 \%$ and the panels began to bend under a load of $368.18 \mathrm{kN}$. Performance values showed that the special bending strength increased by about $111 \%$ and the CSC configuration increased the weight of the sandwich panel by only $3 \%$.
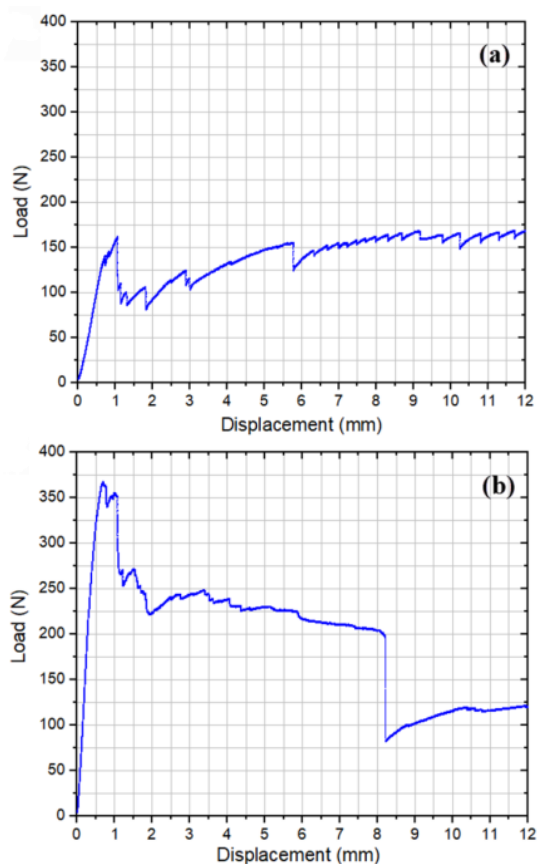

Fig. 7. Load-displacement curves of sandwich panels having (a) $\mathrm{CMC}$ and (b) CSC configurations

TABLE II. BENDING RESPONSE VALUES

\begin{tabular}{|c|c|c|c|c|}
\hline Core Configuration & $\boldsymbol{F}(\mathbf{N})$ & $\boldsymbol{W}(\boldsymbol{g r})$ & $\boldsymbol{\sigma}(\mathbf{M P a})$ & $\boldsymbol{\sigma}_{\boldsymbol{s}}(\mathbf{M P a})$ \\
\hline CMC & 169.11 & 97.64 & 4.12 & 0.04 \\
\hline CSC & 368.18 & 100.76 & 8.98 & 0.08 \\
\hline Percentage of change (\%) & 117.66 & 3.19 & 117.73 & 111.90 \\
\hline
\end{tabular}

\section{B. Failure Modes}

In this section failure modes of the sandwich panels having different core configurations are presented. The loaddisplacement curves of the sandwich panel samples fluctuated. These fluctuations were caused by failures in sandwich panel samples [14]. Upon examining the failures in the sandwich panel samples, it was determined that mainly two different failure modes occurred: buckling of the core wall and debonding of the surface. Debonding of the surface occurred predominantly in the CMC sandwich panels. Buckling of the core wall had not occurred as the core acted as a whole in the bending process. Buckling of the core wall and debonding of surface occurred in the sandwich CSC panels. This was due to the fact that the core was sliced. The dominant failure modes occurring in the sandwich panels are given in Figure 8. The load fluctuations occurring in the load-displacement curves of the sandwich panels consisted of failure modes. In the CMC sandwich panels, debonding between the core and the surface plates was more noticeable because the adhesion proceeded linearly across the panel (Figure 9(a)). This debonding of the surface decreased the strength of the panels. Since the adhesion area of the CSC configuration is small, the debonding of the 
surface was limited and did not proceed through the panel (Figure 9(b)). Therefore, force fluctuations were much lower. The CSC configuration, while maintaining the integrity of the panel, also increased the bending strength of the panel.

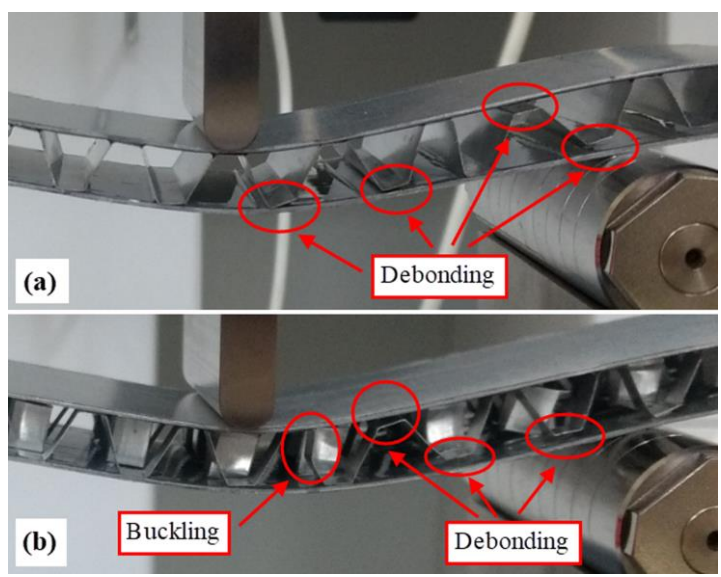

Fig. 8. Dominant failure modes of sandwich panels having different core configurations: (a) CMC and (b) CSC
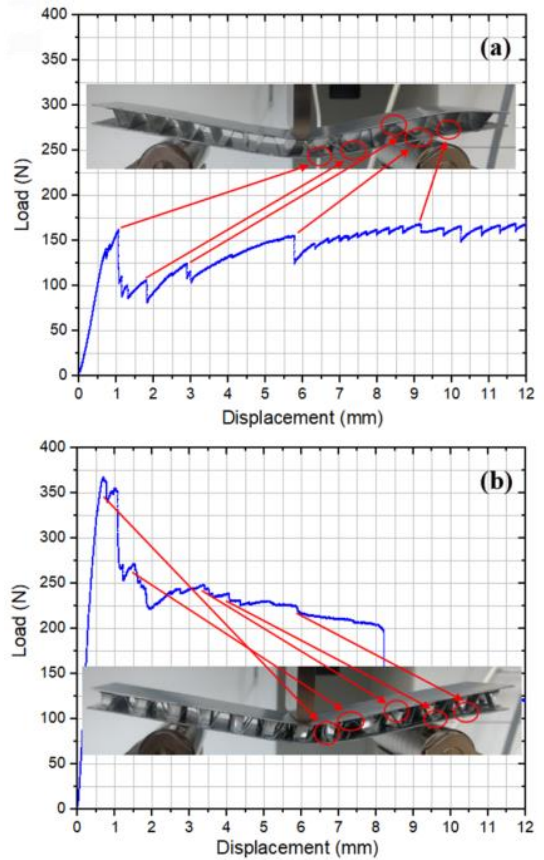

Fig. 9. Load fluctuations in the load-displacement curves of sandwich panels having (a) CMC and (b) CSC configurations

\section{CONCLUSION}

In this study the production of metallic sandwich panel samples having different core configurations was accomplished. The samples were studied experimentally under three-point bending load testing. The test results were examined and compared. The effect of different core configurations on the bending responses of the metallic sandwich panels was determined. The main findings in this study are summarized as:
- The corrugated sliced core configuration increased the bending strength of the sandwich panels.

- The corrugated monolithic core configuration caused the bending load to fluctuate and this reduced the bending strength resistance of the panels.

- The sliced core configuration prevented fluctuations in the load-displacement curve and contributed to the integrity of the panels.

- As the adhesion surface of the corrugated sliced core to the surface plates was small, the debonding of the surface was limited and did not significantly affect the bending strength of the panel.

\section{ACKNOWLEDGMENT}

This work was supported by the Karabuk University Coordinatorship of Scientific Research Projects, Karabuk, Turkey (No. KBUBAP-17-DR-458).

\section{REFERENCES}

[1] R. Mohmmed, A. Ahmed, A. E. Mohamed, H. Ali, "Low velocity impact properties of foam sandwich composites: a brief review", International Journal of Engineering Science and Innovative Technology, Vol. 3, No. 2, pp. 579-591, 2014

[2] J. R. Vinson, The Behavior of Sandwich Structures of Isotropic and Composite Materials, Thechnomic Publishing Co. Inc., 1999

[3] S. Hou, C. Shu, S. Zhao, T. Liu, X. Han, Q. Li, "Experimental and numerical studies on multi-layered corrugated sandwich panels under crushing load", Composite Structures, Vol. 126, pp. 371-385, 2015

[4] J. W. Hutchinson, Z. Xue, "Metal sandwich plates optimized for pressure impulses", International Journal of Mechanical Sciences, Vol. 47, pp. 545-569, 2005

[5] S. Kazemahvazi, D. Zenkert, "Corrugated all-composite sandwich structures. Part 1: Modeling”, Composites Science and Technology, Vol. 69, No. 7-8, pp. 913-919, 2009

[6] G. Lu, T. X. Yu, Energy absorption of structures and materials, Woodhead Publishing Ltd., 2003

[7] S. Hou, S. Zhao, L. Ren, X. Han, Q. Li, "Crashworthiness optimization of corrugated sandwich panels", Materials and Design, Vol. 51, pp. 1071-1084, 2013

[8] I. Dayyani, S. Ziaei-Rad, H. Salehi, "Numerical and experimental investigations on mechanical behavior of composite corrugated core", Applied Composite Materials, Vol. 19, No. 3-4, pp. 705-721, 2012

[9] W. S. Chang, E. Ventsel, T. Krauthammer, J. John, "Bending behavior of corrugated-core sandwich plates", Composite Structures, Vol. 70, No. 1, pp. 81-89, 2005

[10] D. Y. Seong, C. G. Jung, D. Y. Yang, K. J. Moon, D. G. Ahn, "Quasiisotropic bending responses of metallic sandwich plates with bidirectionally corrugated cores", Materials and Design, Vol. 31, No. 6, pp. 2804-2812, 2010

[11] Y. A. Khalid, C. L. Chan, B. B. Sahari, A. M. S. Hamouda, "Bending behaviour of corrugated web beams", Journal of Materials Processing Technology, Vol. 150, No. 3, pp. 242-254, 2004

[12] V. Rubino, V. Deshpande, N. A. Fleck, "The three-point bending of Yframe and corrugated core sandwich beams", International Journal of Mechanical Sciences, Vol. 52, pp. 485-494, 2010

[13] ASTM C393/C393M-16:2016- Standard Test Method for Core Shear Properties of Sandwich Constructions by Beam Flexure, ASTM International, 2016

[14] J. Xiong, L. Ma, A. Stocchi, J. Yang, L. Wu, S. Pan, "Bending response of carbon fiber composite sandwich beams with three dimensional honeycomb cores", Composite Structures, Vol. 108, pp. 234-242, 2014 